development establishments. The analyses are presented after the pattern of the three previous reports, but data are also given on the allocation of Federal funds for research and development in the Government's own laboratories, and in profit- and non-profit-making organizations, including educational institutions. Expenditure on the collection of general purpose statistics is now excluded.

The total U.S. Federal Government expenditure on research and development is estimated at about 2,300 million, 2,400 million and 2,700 million dollars in 1955, 1956 and 1957, respectively. These figures should be increased to $2,900,3,100$ and 3,400 million dollars, respectively, if expenditure from procurement and production appropriations of the. Department of Defense for analogous work in the field of engineering is taken into account. Excluding such expenditure but including pay and allowances for military personnel, these figures would be $2,300,2,500$ and 2,900 million dollars. About 85-90 per cent of the total is for research and development, the balance being for the expansion of research and development plant.

If the Department of Defense is considered a single agency, these funds were administered by twentyfive agencies of the executive branch in 1955 and by twenty-four agencies in 1956 and 1957, agencies engaged in collecting data, training scientists, etc., being no longer included. Individual agencies administer funds ranging from less than 50,000 dollars to about $2,000,000,000$ dollars, but 99 per cent of the expenditure in each of the three years is accounted for by eight agencies, among which the Department of Defense (1,936 million dollars) and the Atomic Energy Commission (529 million dollars) rank first and second, respectively, while the budget of the Department of Health, Education and Welfare (110 million dollars) now exceeds that of the Department of Agriculture (103 million dollars). The National Advisory Committee for Aeronautics $(80$ million dollars) and the Department of the Interior (44 million dollars) come next, while the National Science Foundation, the expenditure of which has risen from 10 million dollars in 1955 to 21 million dollars in 1956 and 43 million dollars in 1957, has now passed the Department of Commerce (24 million dollars), largely due to the funds it administers for the International Geophysical Year, though epart from this it would still retain its place among the eight principal agencies financing research and development.

In scientific fields, the physical sciences (including engineering sciences) continued to claim the major share, the proportion during 1955-57 being 87 per cent compared with 11 per cent for the biological sciences and 2 per cent for the social sciences. Commitments for the physical sciences are estimated to have increased by more than 17 per cent in 1956 and a further increase of 7 per cent is expected in 1957 ; about 95 per cent of funds for use in this field are administered by the Department of Defense, the Atomic Energy Commission and the National Advisory Committee for Aeronautics. Funds for the biological sciences come mainly from the Departments of Health, Education and Welfare; Defense ; the Interior; and the Atomic Energy Commission, Veterans Administration and the National Science Foundation; they increased about 11 per cent in 1956 and are expected to increase about 18 per cent in 1957, when expenditure is estimated as 143 million dollars on medical sciences, 72 million on biological sciences and 54 million dollars on agricultural sciences. Funds for the social sciences, about 40 per cent of which come from the Department of Agriculture, increased by 27 per cent in 1956 and a 20 per cent increase is envisaged in 1957.

Of the total expenditure in 1955,130 million dollars was on basic research, of which $42 \cdot 3$ million was on biological sciences, 85.7 million on physical sciences and $2 \cdot 1$ million dollars on sociel sciences; in 1956 the corresponding figures are estimated at 162 million, 50.5 million, 108.7 million and 2.9 million dollars, and in 1957,215 million, $71 \cdot 8$ million, $138 \cdot 8$ million and 4.5 million dollars, respectively. Expenditure on applied research and development in 1955 was 1,915 million dollars, of which 164 million was on biological sciences, $1,570 \cdot 1$ million on physical sciences, $23 \cdot 3$ million on social sciences and $157 \cdot 2$ million dollars on pay and allowances of military personnel. For 1956, the corresponding figures are estimated at 2,208 million, $178 \cdot 2$ million, $1,835 \cdot 6$ million, $29 \cdot 3$ million and 164.6 million dollars, and for 1957 at 2,336 million, $197 \cdot 3$ million, $1,935 \cdot 8$ million, 34.2 million and 168.9 million dollars, respectively.

In 1956,47 per cent of the total, or 1,110 million dollars, including pay and allowances, was spent within the Federal Government's own institutions, 38 per cent, or 899 million dollars, in profit-making organizations, and 13 per cent, or 304 million dollars, on educational institutions. About 15 per cent of the total was expended in research centres, of which roughly 8 per cent were connected with profit-making organizations, 6 per cent with educational institutions and 1 per cent with non-profit-making organizations.

The report includes graphs of the figures for expenditure on research and development since 1940. Although there is a general tendency for expenditure on research and development to increase, this trend would probably be substantially reduced if the data were expressed in terms of constant prices.

\section{SURGICAL TECHNIQUES IN THE STUDY OF FLORAL MORPHO- GENESIS}

F. CUSICK has described floral ontogenesis in Primula bulleyana and has shown that the application of surgical techniques may contribute to an understanding of some aspects of the observed developments (Trans. Roy. Soc. Edin., 63, 153 ; 1956).

The flower of Primula bulleyana, in its early ontogeny, passes through presepal, primordial-sepal, primordial-stamen and ovarial stages. Petals first appear at either the end of the primordial-stamen stage or the beginning of the ovarial stage. The relatively long presepal stage is conveniently divided into early, mid and late periods. If a flower primordium in the early-presepal stage is bisected with a median incision, the tissue along (and on each side of) the wound typically produces the full sequence of floral parts-sepals, stamens and petals, and an ovary. Bisections of older primordia indicate that the ability to form sepals in this position is lost during the mid-presepal stage; at about the latepresepal stage, the ability to form stamens and petals along the wound is also lost. Paired ovaries (a complete ovary on each side of the cut) still develop 
after most primordial-sepal stage bisections and after a minority of primordial-stamen stage bisections.

In primordia bisected during the ovarial stage, the ovary wall usually develops as two arcs, separated by the wound and widely open above it. These results are interpreted as evidence in favour of the hypothesis that a developing flower passes through a succession of physiological states that permit and regulate the formation of each kind of organ in turn. The sites of new organs are defined by existing ones, or by the creation experimentally of new areas marginal to a new morphogenetic centre. But the nature of the organs formed is more a response to the morphogenetic state of the primordium as a whole.

\title{
PHYSICAL MEASUREMENT OF CONE PIGMENT IN THE LIVING HUMAN EYE
}

\author{
By DR. W. A. H. RUSHTON, F.R.S. \\ Physiological Laboratory, Cambridge
}

$\mathbf{I}_{\text {frite }}^{\mathrm{T}}$ T has long been recognized that twilight vision is mediated by the rods of the retina, and that the by the visual pigment rhodopsin (visual purple). The ensuing photolysis results in bleaching, and upon measurements of this colour-change a great body of knowledge has been built.

Daylight vision with colour discrimination is mediated by the cones, and it is generally believed that these contain visual pigments analogous to rhodopsin. One such pigment, 'iodopsin', has in fact been extracted by Wald ${ }^{1}$ from the predominantly cone eyes of the chick. Its sensitivity is maximal in the yellow-green and it regenerates much faster than does rhodopsin. These are properties likely to be possessed by human cone pigments, but since cones (in the chick) appear to contain extremely little extractable iodopsin, the chance of obtaining detectable quantities from mammalian eyes (where, in general, rods predominate) is not good, and so far attempts have proved unsuccessful. It is therefore satisfactory that an alternative approach seems available, and that physical measurements made upon the normal human eye may give information about the cone pigments of the fovea.

Campbell and $\mathbf{I}^{2}$ were able to develop a technique of ophthalmoscopic densitometry by means of which we could measure the change in rhodopsin density which occurred in any small region of the retina as a result of ehange in the light falling there. A modification of the apparatus has permitted the former conclusions to be confirmed and amplified ${ }^{3}$, and the present account summarizes what seems reliable in an extension to the analysis of the cone pigments in the human eye.

In essence the method is that of ref. 3. Yellow light too weak to bleach the pigments appreciably was passed through a photometric wedge and shone into the eye through one half of the dilated pupil and brought to a focus upon the fovea in a $2.7^{\circ}$ circle contrally fixated. The small fraction of this light which was reflected back from behind the retina and left through the other half of the pupil was caught upon a $45^{\circ}$ mirror and reflected sideways into a redsensitive E.M.I. photomultiplier tube. Since this light had passed twice through the retina it must have suffered absorption by the yellow-absorbing cone pigments there. If, now, these were bleached away by exposure to a strong light the signal received by the photocell would be stronger, and in order to reduce it to its former strength the wedge would have to be displaced to a denser position. The increase in wedge density will clearly be equal to the decrease in the pigment double-density (= density for a double passage).

In practice, a great many precautions must be taken if the change in photocell output is to measure simply the change in the density of the visual pigment. These have already been described ${ }^{3}$, and the present account simply gives in outline the principle upon which it is possible to deduce the change in the density of cone pigments from an analysis of light received from the eye.

(a) The rate of regeneration. The subject fixated continuously for about $10 \mathrm{~min}$. but especially at the moments when the wedge was being set to return the photocell output to its initial value. In Fig. 1 the wedge settings are expressed as the density of wedge interposed (measured downwards) which is the same as the double-density of the photolabile pigment measured upwards from an arbitrary zero. Initially the eye is dark-adapted (though exposure to the moderate artificial lighting of the dark room constitutes 'dark adaptation' for cone pigments; so rapid is their regeneration).

Then a very bright light was shone upon the fovea for 30 sec. and immediately afterwards wedge settings were taken, at first in quick succession, later at longer intervals. As is seen from Fig. 1, there is a sudden change of some 0.15 in density upon bleaching. Regeneration follows a curve of exponential type, which in 90 sec. has half returned and in 5 or 6 min. has reached the initial value.

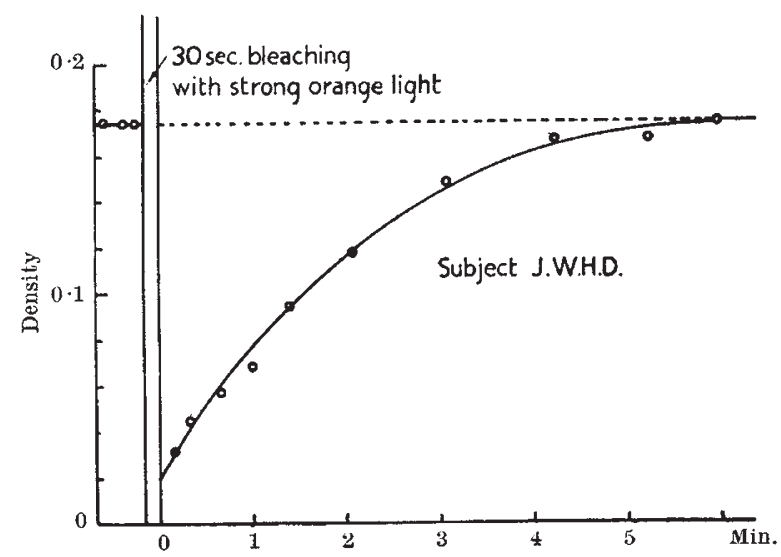

Fig. 1. Ordinates, double-density of foveal visual pigments. Initial values, after dark adaptation. The gap represents $30 \mathrm{sec}$ bleaching with strong orange light (Ilford fliter 203). Density shown. Recovery is complete in $6 \mathrm{~min}$. 